\title{
ОЦЕНКА КОНКУРЕНТОСПОСОБНОСТИ СТРАН ЕВРАЗИЙСКОГО ЭКОНОМИЧЕСКОГО СОЮЗА: ТЕОРИЯ И ПРАКТИКА *
}

\author{
(c) 2020 Абрамов Валерий Леонидович \\ доктор экономических наук, профессор \\ главный научный сотрудник Института исследований международных \\ экономических отношений \\ Финансовый университет при Правительстве Российской Федерации, Россия, Москва \\ E-mail:valabr@yandex.ru
}

Актуальность темы обусловлена важностью и значимостью изучения новых аспектов региональной экономической интеграции (РЭИ), которые проявляются при функционировании ЕАЭС. В статье анализируются теоретические и практические аспекты оценки интеграционных эффектов стран ЕАЭС на основе индексов глобальной конкурентоспособности. Показано, что страны ЕАЭС демонстрируют положительную динамику продвижения в рейтингах глобальной конкурентоспособности, но при этом сильно отличаются по уровню своей международной конкурентоспособности.

Сформулированы теоретические и практические рекомендации по повышению конкурентоспособности национальных экономик стран ЕАЭС, а также интеграционного объединения в целом.

Ключевые слова: конкурентоспособность, региональная эконмическая интеграция, Евразийский экономический союз, ЕАЭС, интеграционные эффекты, глобальная конкурентоспособность.

В современных условиях региональная экономическая интеграция (РЭИ) получила динамичное развитие в международных экономических отношениях и представляет собой сложную многоаспектную систему. Оценка интеграционных эффектов РЭИ, также как и конкурентоспособности национальных экономик, связана с анализом многих параметров и индикаторов, несмотря на определенный крен в сторону анализа торговых и инвестиционных потоков. Комплексность этих двух явлений стала одной из причин отсутствия полноценных исследований их взаимного влияния.

Классический подход к изучению РЭИ содержится в работах Б. Баласса [1;2]. Его методология предполагает сравнение количества товаров с выявленным сравнительным преимуществом «до» и «после» интеграции. В случае, если количество товаров сравнительного преимущества выросло, то эффект от интеграции рассматривается как положительный. При интерпретации полученных результатов важно учитывать, что на формирование набора товаров сравнительного преимущества может оказывать влияние множество факторов. Таким образом, значения показателей «до» и «после» интеграции включают также в себя эффекты изменения этих про- чих факторов. Их оценка усовершенствована экономистом Х.Лизнером [3]. Для оценки динамики изменения внешнеторговых отношений в региональных объединениях используется показатель интенсивности двусторонних товаропотоков, который получил дальнейшее развитие в работах К. Кодзимы, К. Андерсона, Х. Норхейма и других исследователей [4;5]. В современных трудах для оценки эффектов РЭИ Де Лобердье и Л.Ван Лангенховен предлагают использовать прежде всего показатели экономического роста, взаимной торговли, миграции, уровня человеческого развития и потоков капитала [6]. Г.Хуфбауер и Дж.Шотт используют по сути схожие показатели, развивая подход Б.Баласса о стадиях РЭИ [7]. При этом следует отметить, что подходы к оценке интеграционных эффектов достаточно глубоко исследованы в академической литературе, аналитических отчетах международных организаций, институтов развития и наднациональных органов регулирования. Условно можно выделить следующие направления научного анализа проблемы. С эмпирической точки зрения наиболее явные эффекты интеграционных процессов прослеживаются на изменении торговых потоков. В качестве основных причин популярности анализа торговых потоков мож-

\footnotetext{
* Статья подготовлена по результатам выполнения Общеуниверситетской комплексной темы Финансового университета при Правительстве Российской Федерации.
} 
но указать на широкую доступность статистики международной торговли, а также то обстоятельство, что большинство интеграционных объединений в мире представляют собой преференциальные зоны торговли или зоны свободной торговли, которые по своей сути затрагивают только торговый аспект взаимодействия между странами. При этом в теоретическом и практическом аспектах изменения торговых потоков можно рассматривать в качестве интеграционных эффектов первого порядка.

В модифицированных методиках оценки интеграционных эффектов фокус смещается не только на рост товаров сравнительного преимущества, но и на структурные изменения во взаимной и внешней торговле в сторону технологически более сложных товаров. Применительно к ЕАЭС это может быть набор экспортных товаров, экономическая сложность которых больше, чем средняя сложность текущей экспортной корзины ЕАЭС. Рост вклада таких товаров во внешнеторговые потоки в будущем может способствовать улучшению структуры экспорта стран ЕАЭС, что можно рассматривать в качестве положительного эффекта для конкурентоспособности с учетом того, что существенную долю экспорта ЕАЭС на настоящий момент составляют сырьевые товары. Важно отметить, что опираясь на теоретические модели международной торговли, рост торговли в большинстве случаев интерпретируется как позитивный результат для национальных экономик. Заметим, что при этом подходе игнорируются возможные негативные эффекты от усиления торгового взаимодействия.

Оценка уровня конкурентоспособности национальных экономик, входящих в состав интеграционных объединений является одной из наиболее актуальных проблем мировой экономики. Единых подходов и стандартов к определению понятия «конкурентоспособность экономики», методам ее оценки и факторам, влияющим на неё, в мире всё еще не существует, что порождает множество вопросов к сравнению уровня развития и конкурентоспособности экономик стран мира. За последние 30 лет были разработаны различные подходы для оценки факторов конкурентоспособности. Одним из первых академических исследований по конкурентоспособности стало исследование М.Портера в 1990 г. «Конкурентные преимущества национальных экономик», в котором автор выделял факторы конкурентоспособности страны в кон- тексте производительности труда.

С течением времени дискуссия о терминах и подходах к оценке конкурентоспособности не претерпела существенных изменений. Можно отметить два тренда. Во-первых, концепция, которая первоначально применялась только для национальных экономик, все чаще используется на других уровнях, в частности на региональном. Во-вторых, обсуждается вопрос о том, является ли ВВП на душу населения подходящей мерой для определения уровня жизни, что является ключевым фактором в контексте анализа конкурентоспособности через производительность труда. С точки зрения эволюции подходов к оценке конкурентоспособности представляется возможным выделить ряд «традиционных» и «новых» факторов конкурентоспособности.

Наиболее признанным в международной практике подходом к оценке конкурентоспособности стран мира является подход Всемирного экономического форума (ВЭФ), разработанный в рамках Отчета о глобальной конкурентоспособности. В отчете оценивается способность стран обеспечивать высокий уровень благосостояния своим гражданам, что, в свою очередь, зависит от того, насколько продуктивно страна использует имеющиеся ресурсы. Индекс глобальной конкурентоспособности (ИГК) оценивает деятельность различных институтов, реализованные меры политики, и другие факторы, которые определяют устойчивые текущие и среднесрочные уровни экономического благополучия страны и ее населения. В целом, ИГК объединяет макроэкономические и микроэкономические аспекты конкурентоспособности. Индекс глобальной конкурентоспособности Всемирного экономического форума (ВЭФ) за 2010-2019 годы позволяет оценить экономическую ситуацию внутри интеграционной группировки и прояснить конкурентные возможности государств-членов ЕАЭС [8]. По данным за 2010-2019 гг. лидером по конкурентоспособности является российская экономика, которая в анализируемом периоде поднялась в рейтинге на 43 место с 63 позиции в 2010 году. Республика Казахстан занимает вторую позицию (55 место), Республика Армения, показав внушительный рост, оказалась на 3 позиции (69 место). Кыргызская Республика в рассматриваемом периоде значительно улучшила свой конкурентный ранг, но является аутсайдером, находясь на самой низкой позиции (96 место) (Таблица 1). 
Таблица 1. Оценка интеграционных эффектов стран ЕАЭС на основе рейтингов глобальной конкурентоспособности, 2010-2019 гг., ранг.

\begin{tabular}{|c|c|c|c|c|c|c|c|c|c|c|}
\hline \multirow{2}{*}{ Страна } & \multicolumn{10}{|c|}{ Год } \\
\hline & 2010 & 2011 & 2012 & 2013 & 2014 & 2015 & 2016 & 2017 & 2018 & 2019 \\
\hline Количество стран в рейтинге & 139 & 142 & 144 & 148 & 144 & 140 & 138 & 137 & 139 & 143 \\
\hline Республика Армения & 98 & 92 & 82 & 79 & 85 & 82 & 79 & 73 & 70 & 69 \\
\hline Республика Беларусь * & - & - & - & - & - & - & - & - & - & - \\
\hline Республика Казахстан & 72 & 72 & 51 & 50 & 50 & 42 & 53 & 57 & 59 & 55 \\
\hline Кыргызская Республика & 121 & 126 & 127 & 121 & 108 & 102 & 111 & 102 & 97 & 96 \\
\hline Российская Федерация & 63 & 66 & 67 & 64 & 53 & 45 & 43 & 38 & 43 & 43 \\
\hline ЕАЭС & 64 & 67 & 66 & 63 & 53 & 45 & 44 & 40 & 45 & 45 \\
\hline
\end{tabular}

* По Республике Беларусь данные отсутствуют в рейтинге данные отсутствуют.

Источник: составлено авторами на основе данных Всемирного экономического форума

(официальный сайт [https://www.weforum.org/reports/the-global-competitiveness-report-207-201 гг.).

Если рассматривать суммарную конкурентоспособность интеграционного объединения, следует отметить ее существенный рост - она выросла на 19 позиций. Нам представляется что существенный вклад в рост совокупной международной конкурентоспособности внесли интеграционные эффекты. При этом разница в конкурентных позициях национальных экономик страны - лидера и аутсайдера является весьма существенной и составляет величину в 53 единицы. Можно утверждать, что на современном этапе развития интеграционных процессов ЕАЭС они отразились прежде всего на развитии рынка товаров и услуг. Создание единой таможенной территории, отсутствие таможенного контроля упрощают ведение трансграничной торговли, что в свою очередь оказывает влияние на уровень конкуренции на национальных рынках. С развитием интеграционных процессов рынки ЕАЭС становятся более открытыми для предприятий из стран-партнеров по объединению, при этом эффект будет более выраженным в случае, если интеграция развивается в соответствии с концепцией «открытого регионализма», поскольку интеграция способствует росту торгового взаимодействия не только со странами - участниками интеграционного объединения, но и с третьими странами. Функционирование и развитие в рамках ЕАЭС единой таможенной территории, наряду с отсутствием таможенного контроля на внутренних границах ЕАЭС существенно повысило открытость государств-членов к осуществлению внешнеторговой деятельности. Наличие единого технического регулирования позволяет постепенно устранить административные и технические барьеры в торговле, повышать качество и безопасность производимой продукции, ее конкурентоспособность как на внутреннем рынке ЕАЭС, так и на внешних рынках. Кроме того, свобода трансграничной торговли улучшает конкуренцию на рынке, расширяется количество субъектов в секторах экономики, что в перспективе также повышает конкурентоспособность экономики в целом. Положительный эффект может быть достигнут в сфере антимонопольной политики, в том числе посредством обмена опытом и применения наилучших практик в рамках интеграционного объединения. Отметим также, что свободное перемещение товаров, услуг, капитала и рабочей силы в рамках ЕАЭС позволило компенсировать небольшой размер внутреннего рынка, характерный для малых экономик ЕАЭС - Республики Армения и Кыргызской Республики.

\section{Выводы.}

Достигнутые интеграционные эффекты в росте международной конкурентоспособности стран ЕАЭС обусловлены в значительной степени тем, что таможенно-тарифное регулирование в настоящее время осуществляются в значительной степени на наднациональной основе. Однако по уровню своей международной конкурентоспособности страны сильно отличаются, хотя и демонстрируют положительную динамику продвижения в рейтингах глобальной конкурентоспособности.

Для обеспечения более высокого уровня международной конкурентоспособности ЕАЭС объективно необходим переход на более высокий уровень и этап развития интеграционных процессов. В современных условиях одним из ключевых факторов повышения конкурентоспособности национальных экономик является 
уровень инновационной активности. Влияние интеграции на возможности повышения инновационной активности реализуется с точки зрения повышения доступности ресурсов, необходимых для инновационной деятельности (обеспечение разнообразия рабочей силы, финансирование инновационных проектов наднациональными институтами, развитие международного сотрудничества институтов, лабораторий и пр.) Для данного перехода имеются существенные объективные предпосылки и наработки. Деятельность Евразийской экономической комиссии по данному направлению включает в себя реализацию проектов, направленных на содействие и углубление промышленного сотрудничества и кооперации между государствами - членами ЕАЭС с целью стимулирования развития высокотехнологичных производств, создания центров компетенций в интересах повышения глобальной конкурентоспособности промышленного сектора ЕАЭС. Одним из инструментов развития сотрудничества в научно-технической, инновационной и производственной сферах в ЕАЭС стало создание Евразийских технологических платформ и Евразийского инжинирингового центра. Использование в практической деятельности государственных и наднациональных органов ЕАЭС методологии Индекса глобальной конкурентоспособности предоставляет возможности для выявления слабых и сильных сторон национальных экономик в составе интеграционного союза. Методология ИГК позволяет определить необходимые меры, чтобы уменьшить имеющиеся разрывы в конкурентных позициях, обеспечить более высокий уровень международной конкурентоспособности путем развития евразийской промышленной кооперации. Для увеличения интеграционных эффектов, формирования высокой международной конкурентоспособности национальных экономик ЕАЭС необходимо применение инструментов и механизмов взаимодействия по трем основным направлениям: реализация потенциала интегрированных рынков товаров, услуг, капитала и трудовых ресурсов; углубление промышленной кооперации; развитие научно-технического сотрудничества. Интеграционное взаимодействие в данных направлениях будет способствовать повышению конкурентоспособности как национальных экономик, так и интеграционного объединения в целом.

\section{Библиографический список}

1 Balassa, B. The Theory of Economic Integration. London, George Allen, 1969.

2 Balassa, B. (1965) Trade Liberalization and Revealed Comparative Advantage. The Manchester School of Economic and Social Studies, 33 (2), 99-123.

3 Liesner H. The European Common Market and British Industry // Economic Journal. 1968. № 12.

4 Anderson V. Alternative economic indicators. Routledge, London, 1991.

5 Anderson K., Norheim H. From Imperial to Regional Trade Preferences. 1993.

6 De Lombaerde P. and Van Langenhove L. Indicators of Regional Integration: Conceptual and Methodological Aspects, in: De Lombaerde P. (ed), Assessment and Measurement of Regional Integration, London: Routledge, 2006.

7 Hufbauer, G. C. \& Schott, J.J.Western hemisphere economic integration, Institute for International Economics, Washington, D. C. 1994.

8 The Global Competitiveness Report 2017-2018.- Geneva: World Economic Forum. http://reports.weforum.org/ global-competitiveness-index). 